\title{
Prognostic significance of altered expression of SDC2 and CYR61 in esophageal squamous cell carcinoma
}

\author{
XIN HUANG ${ }^{1 *}$, DA-WEI XIAO ${ }^{2 *}$, LI-YAN XU ${ }^{3}$, HAI-JUN ZHONG ${ }^{2}$, \\ LIAN-DI LIAO ${ }^{3}$, ZE-FEN XIE ${ }^{2}$ and EN-MIN LI ${ }^{1}$ \\ Departments of ${ }^{1}$ Biochemistry and Molecular Biology, ${ }^{2}$ Cardiothoracic Surgery of the First Affiliated Hospital, \\ ${ }^{3}$ Institute of Oncologic Pathology, Medical College of Shantou University, Shantou 515041, P.R. China
}

Received December 3, 2008; Accepted January 7, 2009

DOI: 10.3892/or_00000332

\begin{abstract}
The transforming growth factor $\beta$ (TGF- $\beta$ ) signaling pathway plays an important role in growth and development, and is critically involved in the genesis and development of tumors. Syndecan-2 (SDC2) and Cysteine-rich 61 (CYR61) are important genes in this pathway and SDC2 is known to be a significant upstream regulator of TGF- $\beta$ signaling. However, the roles of SDC2 and CYR61 in the development of esophageal squamous cell carcinoma (ESCC) remain unclear. In the present study, we investigated the relationship between SDC2 and CYR61 mRNA expression levels and disease prognosis in patients with ESCC. The mRNA expression of SDC2 and CYR61 was detected by quantitative real-time RT-PCR in 77 tissue specimens. Quantitative realtime RT-PCR showed that SDC2 and CYR61 mRNA expression levels were aberrant in ESCC tissue $(\mathrm{P}<0.01)$ and that SDC2 mRNA expression was significantly associated with tumor size $(\mathrm{P}=0.024)$ in ESCC. CYR61 mRNA expression was significantly associated with regional lymph node metastasis $(\mathrm{P}=0.034)$ and tumor size $(\mathrm{P}=0.03)$. A positive correlation between SDC2 and CYR61 ( $\mathrm{r}=0.770$; $\mathrm{P}<0.001)$ mRNA expression was observed. Moreover, we observed significant associations between altered expression of SDC2/CYR61 and regional lymph node metastasis $(\mathrm{P}=0.009)$ and TNM stages $(\mathrm{P}=0.033)$. Aberrant mRNA expression of CYR61 and SDC2/CYR61 ( $\mathrm{P}=0.005$ and $\mathrm{P}=0.026$, respectively) were significantly associated with
\end{abstract}

Correspondence to: Dr En-Min Li, Department of Biochemistry and Molecular Biology, Medical College of Shantou University, No.22, XinLing Road, Shantou 515041, P.R. China

E-mail:nmli@stu.edu.cn

Dr Li-Yan Xu, Institute of Oncologic Pathology, Medical College of Shantou University, No.22, XinLing Road, Shantou 515041, P.R. China

E-mail: liyanxu1130@yahoo.com.cn

${ }^{*}$ Contributed equally

Key words: SDC2, CRY61, TGF-ß signaling pathway, esophageal squamous cell carcinoma, quantitative real-time RT-PCR patient survival time. The multivariate Cox regression analysis showed that SDC2 and CYR61 were independent prognostic factors for survival. Our findings suggest that SDC2 may act as an a upstream regulator of the TGF- $\beta$ signaling pathway and regulate the expression of downstream target genes. Moreover, SDC2 and CYR61 expression affect the severity of cancer, and the survival of patients with ESCC. Importantly, we report that SDC2 and CYR61 are significant, independent prognostic factors for survival in ESCC. These findings may have implications for targeted therapies in patients with ESCC.

\section{Introduction}

Esophageal squamous cell carcinoma (ESCC) is the most common malignancy in China, and has high mortality. It is difficult to diagnose ESCC during early stages of disease development, and advanced ESCC is frequently associated with local invasion of lymph nodes and lymph node metastasis (1).

Previous studies have proposed important roles for various signaling pathways in tumorigenesis and development of ESCC. For example, end-binding protein 1 (EB1) over-expression may contribute to the development of ESCC by activating the $\beta$-catenin/TCF pathway (2). Another report demonstrated that the Notch1 signaling pathway is activated in ESCC, and that it can inhibit cell proliferation and induce apoptosis in human ESCC cells (3). Studies from Noma et al showed that pharmacologic targeting of the TGF- $\beta$ signaling axis could be of therapeutic benefit in ESCC (4).

Syndecan-2 (SDC2) functions as a cell surface receptor in the regulation of adhesion-dependent signal transduction during cell growth, adhesion, migration, and differentiation through binding of the extracellular matrix (ECM) and/or soluble ligands (5). SDC2 is a significant upstream regulator of the TGF- $\beta$ signaling pathway (6), regulating signaling by acting as a co-receptor for growth factors. SDC2 facilitates signaling by forming a ternary complex with TGF- $\beta$ and its signaling receptors, TGFRI and TGFRII (7-9). This protein plays diverse roles in tumorigenesis. Previous studies of colon cancer and mesothelioma cells have shown that SDC2 was up-regulated in these cells, compared to normal tissues (10-12). However, Munesue et al transfected SDC2 into 
potentially metastatic cells derived from Lewis lung carcinoma 3LL, and reported the suppression of both spontaneous and experimental metastases to the lung through suppression of the matrix metalloproteinase-2 (MMP-2) (13). In spite of these advances, the expression levels and mechanisms of action of the genes in the TGF- $\beta$ signaling pathway, including SDC2, remain unclear in ESCC.

Recent studies have shown that Cysteine-rich 61 (CYR61) is a transcriptional target of the TGF- $\beta$ signaling pathway (14). CYR61 is a member of the CCN family and is known to regulate cell growth, cell migration, cell adhesion, cellular differentiation and matrix production (15), as well as angiogenesis and tumorigenesis. Similarly to SDC2, the roles of CYR61 in tumorigenesis are diverse. Down-regulation of CYR61 expression is associated with non-small cell lung carcinoma, uterine leiomyoma, endometrial cancer, and prostate cancer. Chien et al have reported that the levels of CYR61 are decreased in endometrial tumors, as compared with normal endometrium. Furthermore, RNA interference knockdown of CYR61 expression in a well-differentiated endometrial adenocarcinoma cell line resulted in stimulation of cellular growth (16). On the other hand, over-expression of CYR61 is also frequently noted in advanced breast cancer, pancreatic cancer, gastric cancer and gliomas. Tsai et al have shown that CYR61 is a tumor-promoting factor and a key regulator of breast cancer progression (17). Xie et al have demonstrated that overexpression of CYR61 occurred in highly tumorigenic glioma cell lines and that CYR61 can enhance tumorigenicity of glioma cells by acting through activated integrin-linked kinase (ILK) to stimulate $\beta$-cateninTCF/Lef and Akt signaling pathways (18). Di Martino et al have reported that during the development of Barrett's esophagus and esophageal adenocarcinoma (EAC), CYR61 is up-regulated and has been investigated as a marker of EAC risk (19).

Based on these previous studies of SDC2 and CYR61 expression in various tumor tissues and cloned cell lines, the objectives of the present study were to investigate the expression of SDC2 and CYR61 in ESCC, and the relationship between their expression and the clinical characteristics of ESCC, their prognostic significance, and patient survival.

\section{Materials and methods}

Patients and tissue specimens. ESCC tissue specimens and paired adjacent normal epithelial tissues were obtained from 77 patients (median age, 55 years, range 40-74) who underwent surgery in the Department of Cardiothoracic Surgery of the First Affiliated Hospital of Shantou University between September of 2004 and August of 2007. The specimens were immediately frozen in liquid nitrogen following surgery and stored at $-70^{\circ} \mathrm{C}$ until RNA isolation. All of the tumors were confirmed as ESCC by the Clinical Pathology Department of the Hospital, and the cases were classified according to the fifth edition of the tumor-nodemetastasis classification of the International Union against Cancer (UICC). Evaluation of tumor differentiation was based on histological criteria of the guidelines of the WHO Pathological Classification of Tumors. The study was approved by the Ethics committee of the First Affiliated
Table I. Clinicopathological features of patients with ESCC.

Parameters

\begin{tabular}{lc}
\hline Mean age, years (range) & $55(40-74)$ \\
$<55$ & 42 \\
$\geq 55$ & 35 \\
Gender & \\
$\quad$ Male & 62 \\
Female & 15 \\
Size & \\
$\quad$ 5 & 40 \\
$>5$ & 37 \\
Regional lymph node & \\
N0 & 42 \\
N1 & 35 \\
Infiltration degree & \\
T1 + T2 & \\
T4 + T3 & 25 \\
P-Stage & 52 \\
I + IIa + IIb & \\
III + IV & 51 \\
\hline
\end{tabular}

Table II. The distribution number of ESCC specimens for CYR61 and SDC2 mRNA expression levels.

\begin{tabular}{lcccc}
\hline Genes & $2^{-\Delta \Delta C \mathrm{CT}} \geq 2$ & $2>2^{-\Delta \Delta C \mathrm{CT}}>0.5$ & $2^{-\Delta \Lambda \mathrm{CT}} \leq 0.5$ & P-value \\
\hline CYR61 & $43 \%(33 / 77)$ & $36 \%(28 / 77)$ & $21 \%(16 / 77)$ & $0.023^{\mathrm{a}}$ \\
SDC2 & $44 \%(34 / 77)$ & $29 \%(22 / 77)$ & $27 \%(21 / 77)$ & $0.009^{\mathrm{a}}$ \\
\hline
\end{tabular}

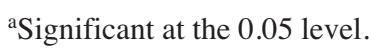

Hospital of Shantou University, and only patients with written informed consent were included. None of the patients had radiotherapy or chemotherapy before surgery (Table I). Seventy-seven patients were monitored until January of 2008 , and $23(30 \%)$ patients had died at the end of the follow-up period.

RNA extraction and cDNA preparation. Total RNA was extracted from frozen stored tissues with TRIzol reagent (Invitrogen, USA) in accordance with the manufacturer's instructions. Reverse transcription was performed in a total volume of $20 \mu \mathrm{l}$ using $1 \mu \mathrm{g}$ of total RNA by using the Reverse Transcription System (Promega, USA).

Quantitative real-time RT-PCR. All PCR reactions were performed using an ABI Prism 7300 Sequence Detection System (Perkin-Elmer Applied Biosystems) based on the TaqMan technology. For the normalization of our results, B-actin was used as the internal control. Primers and probes for CYR61, SDC2 and ß-actin were chosen with the assistance 
Table III. Relationship between clinicopathological features and CYR61 mRNA expression.

\begin{tabular}{|c|c|c|c|c|}
\hline \multirow[b]{2}{*}{ Parameters } & \multicolumn{3}{|c|}{ CYR61 status } & \multirow[b]{2}{*}{ P-value } \\
\hline & $2^{-\Delta \Delta \mathrm{CT}} \geq 2$ & $2>2^{-\triangle \triangle C T}>0.5$ & $2^{-\triangle \Delta \mathrm{CT}} \leq 0.5$ & \\
\hline \multicolumn{5}{|l|}{ Gender } \\
\hline Male & $47 \%(29 / 62)$ & $34 \%(21 / 62)$ & $19 \%(12 / 62)$ & 0.369 \\
\hline Female & $26.7 \%(4 / 15)$ & $46.6 \%(7 / 15)$ & $26.7 \%(4 / 15)$ & \\
\hline \multicolumn{5}{|l|}{ Mean age } \\
\hline$<55$ & $50 \%(21 / 42)$ & $29 \%(12 / 42)$ & $21 \%(9 / 42)$ & 0.264 \\
\hline$\geq 55$ & $34 \%(12 / 35)$ & $46 \%(16 / 35)$ & $20 \%(7 / 35)$ & \\
\hline \multicolumn{5}{|l|}{ Size $(\mathrm{cm})$} \\
\hline$\leq 5$ & $35 \%(14 / 40)$ & $32.5 \%(13 / 40)$ & $32.5 \%(13 / 40)$ & $0.03^{\mathrm{a}}$ \\
\hline$>5$ & $51 \%(19 / 37)$ & $41 \%(15 / 37)$ & $8 \%(3 / 37)$ & \\
\hline \multicolumn{5}{|c|}{ Regional lymph node } \\
\hline No & $55 \%(23 / 42)$ & $33 \%(14 / 42)$ & $12 \%(5 / 42)$ & $0.034^{\mathrm{a}}$ \\
\hline $\mathrm{N} 1$ & $29 \%(10 / 35)$ & $40 \%(14 / 35)$ & $31 \%(11 / 35)$ & \\
\hline \multicolumn{5}{|c|}{ Infiltration degree } \\
\hline $\mathrm{T} 1+\mathrm{T} 2$ & $44 \%(11 / 25)$ & $36 \%(9 / 25)$ & $20 \%(5 / 25)$ & 0.988 \\
\hline $\mathrm{T} 3+\mathrm{T} 4$ & $42 \%(22 / 52)$ & $37 \%(19 / 52)$ & $21 \%(11 / 52)$ & \\
\hline \multicolumn{5}{|l|}{ P-Stage } \\
\hline $\mathrm{I}+\mathrm{IIa}+\mathrm{IIb}$ & $49 \%(25 / 51)$ & $35 \%(18 / 51)$ & $16 \%(8 / 51)$ & 0.195 \\
\hline III + IV & $30 \%(8 / 26)$ & $39 \%(10 / 26)$ & $31 \%(8 / 26)$ & \\
\hline
\end{tabular}

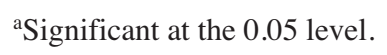

of Primer Express 2.0 software (Perkin-Elmer Applied Biosystems). To avoid amplification of contaminating genomic DNA, one of the two primers of each gene were intron spanning. The PCR primers used for CYR61 and SDC2 were as follows: For SDC2, the forward primer was 5'-CCTATTG ATGACGATGACTACGC-3' and the reverse primer was 5'-TTTGGAAGTGGTCGAGATGTTG-3'. For CYR61, the forward primer was 5'-ATGAATTGATTGCAGTTGGA AA-3' and the reverse primer was 5'-TAAAGGGTTGTAT AGGATGCGA-3'. According to the gene sequence of SDC2 and CYR61, the PCR products of $95 \mathrm{bp}$ and $86 \mathrm{bp}$ were obtained. For $B$-actin, the forward primer was 5'-CAACTG GGACGACATGGAGAAA-3' and the reverse primer was 5'-GATAGCAACGTACATGGCTGGG-3'. The sequence of TaqMan probes were as follows: 5'-TCTGGCTCGGGAG CTGATGAGGAT-3' for SDC2 5'-AGCTCACTGAAGCGG CTCCCTGTTT-3' for CYR61, and 5'-TCTGGCACCAC ACCTTCTACAATGAGC-3' for $\beta$-actin. The $25 \mu 1$ volume PCR reaction mixture containing $5 \mu 1 \mathrm{cDNA}$ sample was preheated at $95^{\circ} \mathrm{C}$ for $10 \mathrm{~min}$, followed by 40 cycles at $95^{\circ} \mathrm{C}$ for $15 \mathrm{sec}$ and $60^{\circ} \mathrm{C}$ for $1 \mathrm{~min}$. Data were analyzed using Sequence Detector Systems version 2.0 software (Applied Biosystems). Quantification was performed using the $2^{-\Delta \Delta C T}$ method. The comparative threshold cycle $\left(\mathrm{C}_{\mathrm{T}}\right)$ method was used to calculate the relative expression. For quantification of gene expression, the target gene values were normalized to the expression of the endogenous reference ( $\beta$-actin). Thus, the amount of target relative to a calibrator (normal pool expression) is given by $2^{-\Delta \Delta C T}\left[\Delta C_{T}=C_{T}\right.$ (target gene) $-C_{T}$ (ß-actin); $\Delta \Delta \mathrm{C}_{\mathrm{T}}=\Delta \mathrm{C}_{\mathrm{T}}$ for any sample $\Delta \mathrm{C}_{\mathrm{T}}$ for the calibrator]. The status of each differentially expressed CYR61 and SDC2 gene in the ESCC tissue was defined as 'aberrant expression' if $2^{-\triangle \Delta C T}$ was $\geq 2$-fold or $\leq 0.5$-fold, when compared to that detected in the adjacent normal tissue and as 'normal expression' if 2 was $<2$-fold and $>0.5$-fold.

Statistical analysis. Statistical analyses were performed using windows SPSS version 13.0 software. After performing quantitative real-time RT-PCR, the extent of SDC2 and CYR61 mRNA expression was analyzed by using a paired sample t-test. The relationship between SDC2 and CYR61 status and clinicopathological features, including TNM stage, age, lymph node dissemination, and infiltration degree, were analyzed using $\chi^{2}$ test. Survival analysis was carried out using the log-rank test in association with Kaplan-Meier analysis and Cox proportional hazards model analysis. Differences at P-value $<0.05$ were deemed statistically significant in all analyses.

\section{Results}

To assess the clinical implications of SDC2 and CYR61 mRNA expression in ESCC, we analyzed expression of these genes in 77 ESCCs cancer tissues and paired adjacent normal epithelial tissues. The number of ESCC specimens for SDC2 and CYR6 with 'aberrant mRNA expression' was significantly higher than that of 'normal mRNA expression' $(\mathrm{P}=0.009$ and $\mathrm{P}=0.023)$ (Table II). 
Table IV. Relationship between clinicopathological features and SDC2 mRNA expression.

\begin{tabular}{|c|c|c|c|c|}
\hline \multirow[b]{2}{*}{ Parameters } & \multicolumn{3}{|c|}{ CYR61 status } & \multirow[b]{2}{*}{ P-value } \\
\hline & $2^{-\Delta \Delta C T} \geq 2$ & $2>2^{-\triangle \Delta C T}>0.5$ & $2^{-\triangle \Delta \mathrm{CT}} \leq 0.5$ & \\
\hline \multicolumn{5}{|l|}{ Gender } \\
\hline Male & $47 \%(29 / 62)$ & $29 \%(18 / 62)$ & $24 \%(15 / 62)$ & 0.444 \\
\hline Female & $33 \%(5 / 15)$ & $27 \%(4 / 15)$ & $40 \%(6 / 15)$ & \\
\hline \multicolumn{5}{|l|}{ Mean age } \\
\hline$<55$ & $47.6 \%(20 / 42)$ & $28.6 \%(12 / 42)$ & $23.8 \%(10 / 42)$ & 0.720 \\
\hline$\geq 55$ & $40 \%(14 / 35)$ & $28.6 \%(10 / 35)$ & $31.4 \%(11 / 35)$ & \\
\hline \multicolumn{5}{|l|}{ Size $(\mathrm{cm})$} \\
\hline$\leq 5$ & $30 \%(12 / 40)$ & $32.5 \%(13 / 40)$ & $37.5 \%(15 / 40)$ & $0.024^{\mathrm{a}}$ \\
\hline$>5$ & $59.5 \%(22 / 37)$ & $24.3 \%(9 / 37)$ & $16.2 \%(6 / 37)$ & \\
\hline \multicolumn{5}{|c|}{ Regional lymph node } \\
\hline No & $52 \%(22 / 42)$ & $31 \%(13 / 42)$ & $17 \%(7 / 42)$ & 0.067 \\
\hline $\mathrm{N} 1$ & $34 \%(12 / 35)$ & $26 \%(9 / 35)$ & $40 \%(14 / 35)$ & \\
\hline \multicolumn{5}{|c|}{ Infiltration degree } \\
\hline $\mathrm{T} 1+\mathrm{T} 2$ & $40 \%(10 / 25)$ & $32 \%(8 / 25)$ & $28 \%(7 / 25)$ & 0.859 \\
\hline $\mathrm{T} 3+\mathrm{T} 4$ & $46 \%(24 / 52)$ & $27 \%(14 / 52)$ & $27 \%(14 / 52)$ & \\
\hline \multicolumn{5}{|l|}{ P-Stage } \\
\hline $\mathrm{I}+\mathrm{IIa}+\mathrm{IIb}$ & $47 \%(24 / 51)$ & $31 \%(16 / 51)$ & $22 \%(11 / 51)$ & 0.286 \\
\hline III + IV & $38.5 \%(10 / 26)$ & $23 \%(6 / 26)$ & $38.5 \%(10 / 26)$ & \\
\hline
\end{tabular}

aSignificant at the 0.05 level.

Table V. Relationship between clinicopathological features and CYR61/SDC2 mRNA expression.

\begin{tabular}{|c|c|c|c|c|}
\hline \multirow[b]{2}{*}{ Parameters } & \multicolumn{3}{|c|}{ CYR61/SDC2 status } & \multirow[b]{2}{*}{ P-value } \\
\hline & $2^{-\Delta \Delta C T} \geq 2$ & $2>2^{-\Delta \Delta C \mathrm{CT}}>0.5$ & $2^{-\triangle \Delta C \mathrm{~T}} \leq 0.5$ & \\
\hline \multicolumn{5}{|l|}{ Gender } \\
\hline Male & $30.6 \%(19 / 62)$ & $58 \%(36 / 62)$ & $11.3 \%(7 / 62)$ & 0.665 \\
\hline Female & $26.7 \%(4 / 15)$ & $53.3 \%(8 / 15)$ & $20 \%(3 / 15)$ & \\
\hline \multicolumn{5}{|l|}{ Mean age } \\
\hline$<55$ & $33.3 \%(14 / 42)$ & $52.4 \%(22 / 42)$ & $14.3 \%(6 / 42)$ & 0.651 \\
\hline$\geq 55$ & $25.7 \%(9 / 35)$ & $62.9 \%(22 / 35)$ & $11.4 \%(4 / 35)$ & \\
\hline \multicolumn{5}{|l|}{ Size } \\
\hline$\leq 5$ & $20 \%(8 / 40)$ & $65 \%(26 / 40)$ & $15 \%(6 / 40)$ & 0.144 \\
\hline$>5$ & $40.5 \%(15 / 37)$ & $48.4 \%(18 / 37)$ & $10.8 \%(4 / 37)$ & \\
\hline \multicolumn{5}{|c|}{ Regional lymph node } \\
\hline NO & $35.7 \%(15 / 42)$ & $61.9 \%(26 / 42)$ & $2.4 \%(1 / 42)$ & $0.009^{\mathrm{a}}$ \\
\hline $\mathrm{N} 1$ & $22.9 \%(8 / 35)$ & $51.4 \%(18 / 35)$ & $25.7 \%(9 / 35)$ & \\
\hline \multicolumn{5}{|c|}{ Infiltration degree } \\
\hline $\mathrm{T} 1+\mathrm{T} 2$ & $32 \%(8 / 25)$ & $56 \%(14 / 25)$ & $12 \%(3 / 25)$ & 0.955 \\
\hline $\mathrm{T} 3+\mathrm{T} 4$ & $28.8 \%(15 / 52)$ & $57.7 \%(30 / 52)$ & $13.5 \%(7 / 52)$ & \\
\hline \multicolumn{5}{|l|}{ P-Stage } \\
\hline $\mathrm{I}+\mathrm{IIa}+\mathrm{IIb}$ & $33.3 \%(17 / 51)$ & $60.8 \%(31 / 51)$ & $5.9 \%(3 / 51)$ & $0.033^{\mathrm{a}}$ \\
\hline $\mathrm{III}+\mathrm{IV}$ & $23 \%(6 / 26)$ & $50 \%(13 / 26)$ & $26.9 \%(7 / 26)$ & \\
\hline
\end{tabular}

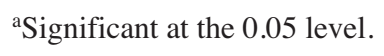




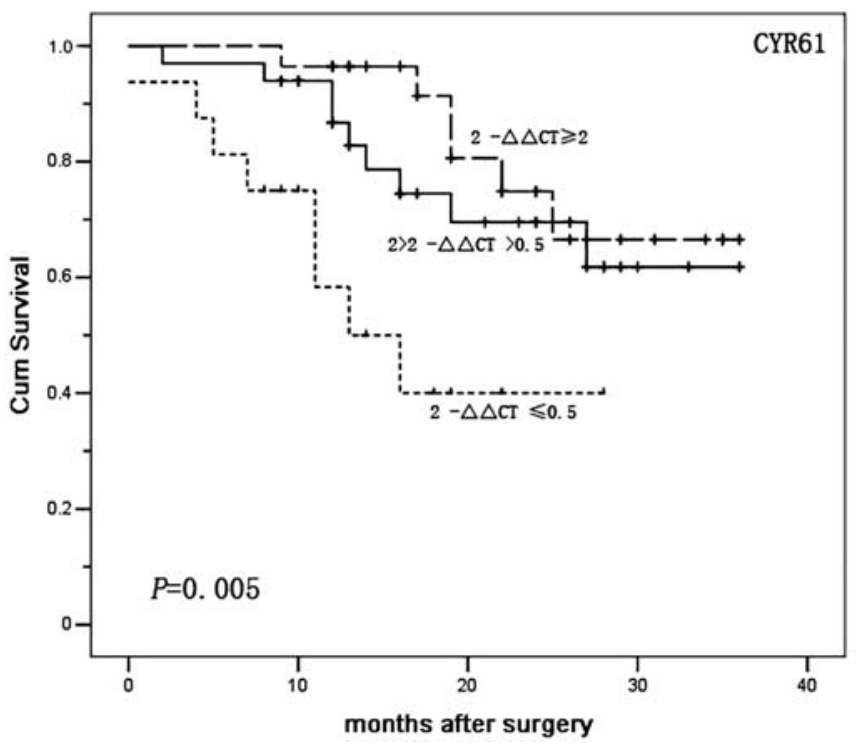

Figure 1. Kaplan-Meier survival curves for CRY61. The Kaplan-Meier analyses of CRY61 mRNA expression in 77 patients with ESCC illustrate that survival was lower in cases where CYR61 mRNA expression was down-regulated, as compared with cases where CYR61 expression was normal or up-regulated $(\mathrm{P}=0.005)$.

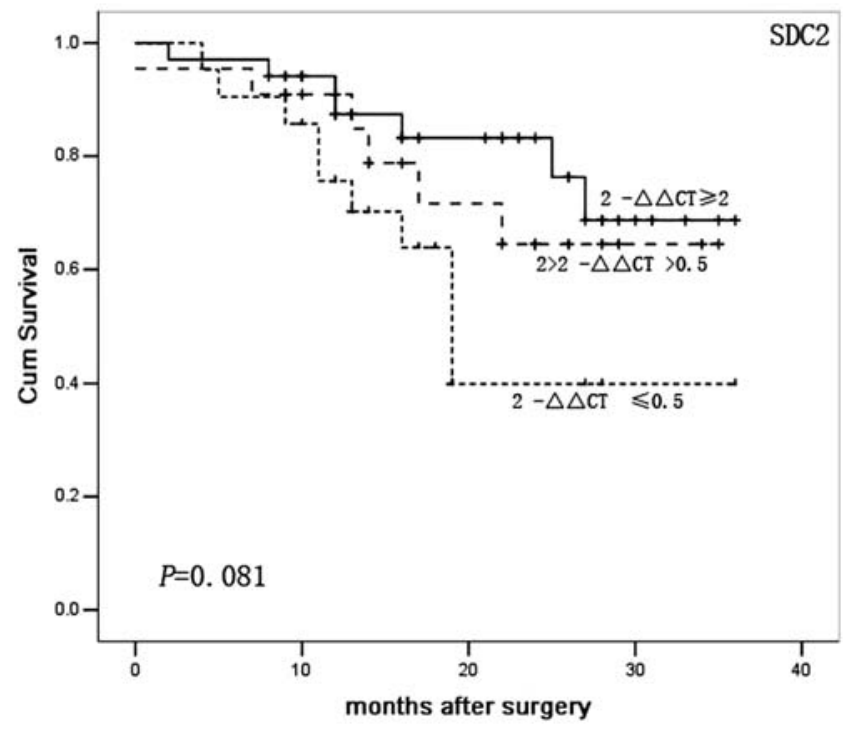

Figure 2. Kaplan-Meier survival curves for SDC2. The Kaplan-Meier analyses of SDC2 mRNA expression in 77 patients with ESCC illustrate that there was no correlation between SDC2 mRNA expression and survival $(\mathrm{P}=0.081)$.

Clinical and pathological variable analysis. We analyzed the relationship between SDC2 and CYR61 mRNA expression, and clinical and pathological variables, including gender, mean age, tumor size, lymph node dissemination, infiltration degree and TNM stage analysis of ESCC, using Pearson $\chi^{2}$ test. We identified significant associations between CYR61 mRNA expression and regional lymph node metastasis and tumor size $(\mathrm{P}<0.05$, Table III). SDC2 mRNA expression was significantly associated with tumor size $(\mathrm{P}=0.024$, Table IV), but not regional lymph node metastasis. Moreover, positive

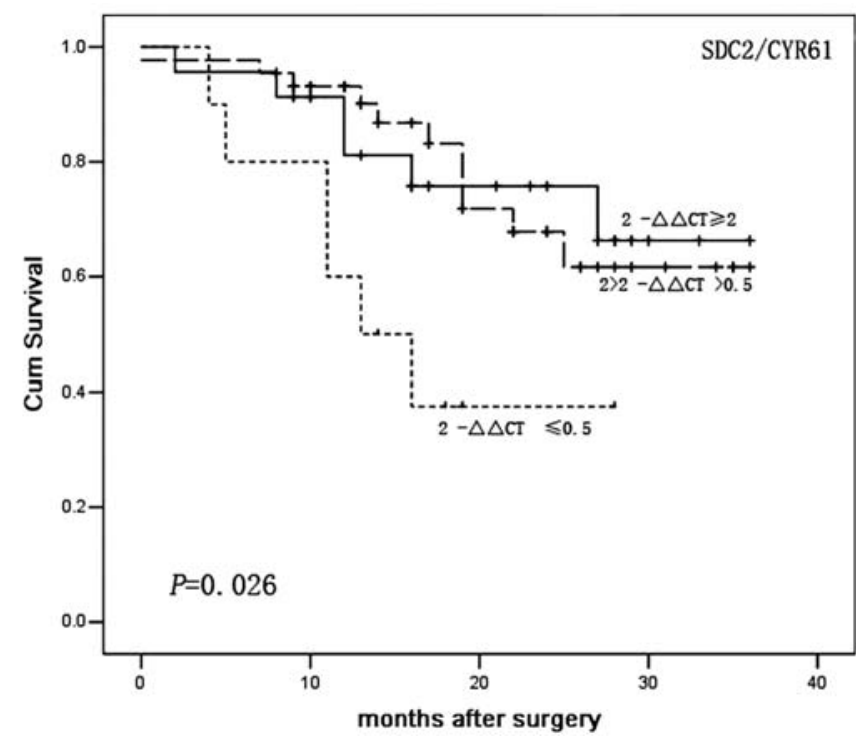

Figure 3. Kaplan-Meier survival curves for SDC2/CYR61. The KaplanMeier analyses of SDC2/CYR61 mRNA expression in 77 patients with ESCC illustrate that survival was lower in cases where SDC2 and CYR61 mRNA expression were both down-regulated, as compared with cases in which SDC2 and CYR61 were both normal or up-regulated $(\mathrm{P}=0.026)$.

correlations between SDC2 and CYR61 mRNA expression were observed in the 77 ESCC cases $(r=0.770 ; \mathrm{P}<0.001)$. Those cases in which SDC2 and CYR61 together (SDC2/

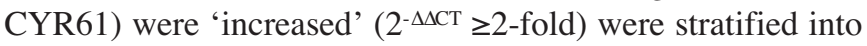
group I. Cases in which both were 'reduced' ( $2^{-\Delta \Delta \mathrm{CT}} \leq 0.5$-fold) were stratified into group II, and the rest of the cases were input into group III for further analysis of the relationship between SDC2/CYR61 mRNA expression and clinical factors. We found significant associations between SDC2/CYR61 mRNA expression status and regional lymph node metastasis and TNM stages $(\mathrm{P}=0.009$ and $\mathrm{P}=0.033$, Table $\mathrm{V})$.

Survival lifespan analysis. We used Kaplan-Meier analyses of SDC2 and CYR61 mRNA expression and SDC2/CYR61 mRNA expression in 77 patients with ESCC. Figs. 1 and 3 illustrate the Kaplan-Meier survival curve as a function of CYR61 and SDC2/CYR61 mRNA expression ( $\mathrm{P}=0.005$ and $\mathrm{P}=0.026$ respectively). CYR61 and SDC2/CYR61 mRNA down-regulation correlated with lower survival rates. There was no correlation between SDC2 mRNA expression and survival ( $\mathrm{P}=0.081$; Fig. 2).

Multivariate analysis. Using the Cox proportional hazards model, we performed multivariate analysis to assess the independent predictive value of SDC2 and CYR61 mRNA expression for survival after surgery. The following prognostic variables were also included: gender, age, size of tumor, regional lymph node metastasis, primary tumor and P-Stage. The results for the multivariate survival analysis are summarized in Table VI. In the 77 patients with ESCC, low levels of SDC2 mRNA expression were significantly associated with survival after surgery $(\mathrm{P}=0.013)$. Similarly, CYR61 $(\mathrm{P}=0.031)$ was also an independent prognostic factor of survival after surgery (Table VI). 
Table VI. Multivariate Cox regression analyses by CYR61 and SDC2 expression levels.

\begin{tabular}{|c|c|c|c|c|}
\hline Univariate & $\begin{array}{l}\text { Mean for survival time } \\
\text { (months) }\end{array}$ & $\begin{array}{l}\text { Percentage of survival } \\
\text { (95\% confidence interval) }\end{array}$ & & P-value \\
\hline \multicolumn{5}{|l|}{ SDC2 } \\
\hline $2^{-\Delta \triangle C T} \geq 2$ & 30.3 & $79.4 \%(26.6-34)$ & - & \\
\hline $2>2^{-\Delta \Lambda C T}>0.5$ & 27.3 & $72.7 \%(22.1-32.5)$ & - & 0.013 \\
\hline $2^{-\Delta \triangle C T} \leq 0.5$ & 22.6 & $52.4 \%(17-28)$ & - & \\
\hline \multicolumn{5}{|l|}{ CYR61 } \\
\hline $2^{-\Delta \triangle C T} \geq 2$ & 28.2 & $72.7 \%(24-32.4)$ & - & \\
\hline $2>2^{-\Delta \Delta C T}>0.5$ & 30.5 & $78.6 \%(26.8-34.2)$ & - & 0.046 \\
\hline $2^{-\triangle \triangle C T} \leq 0.5$ & 16.7 & $50 \%(11.4-22)$ & - & \\
\hline Multivariate variable & B & Hazard ratio & $95 \%$ confidence interval & P-value \\
\hline $\mathrm{SDC} 2$ & -0.715 & 0.489 & $0.277-0.863$ & $0.013^{\mathrm{a}}$ \\
\hline CYR61 & -0.618 & 0.539 & $0.308-0.946$ & $0.031^{\mathrm{a}}$ \\
\hline
\end{tabular}

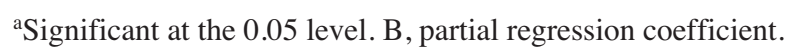

\section{Discussion}

SDC2 has been implicated in cancer cell growth, invasion, metastasis, and angiogenesis. Park et al found that increased expression of SDC2 is crucial for increased rates of colon carcinoma cell proliferation (11). However, the inhibitory effect of SDC2 in tumors was identified in Lewis lung carcinoma through suppression of MMP-2 activation causing suppression of metastasis (13). These studies indicate that SDC2 plays diverse, and possibly conflicting roles, in migratory and highly differentiated cell types. In the present study of 77 patients with ESCC, we found that SDC2 mRNA expression level was correlated with tumor size. Importantly, SDC2 can be considered an independent prognostic factor for survival of ESCC after surgery. These results indicate that SDC2 mRNA down-regulation in ESCC is related to a poor prognosis, and that SDC2 has anti-oncogenic activity in ESCC.

CYR61 is a secreted, heparin-binding and extracellular matrix-associated angiogenic inducer. It regulates cell adhesion, migration, proliferation, and differentiation and is involved in tumor growth. CYR61 was confirmed as both a suppressor and a promoter of progression and tumor invasion. CYR61 can enhance tumor growth in a gastric adenocarcinoma cell line RF-1 and breast cancer cell lines $(20,21)$. However, several gain- and loss-of-function studies have shown that CYR61 can suppress carcinogenesis. Tong et al have reported that CYR61 behaved as a tumor suppressor gene in non-small cell lung cancer (NSCLC); expression of CYR61 in the NSCLC cell lines resulted in their growth arrest and up-regulation of p53, p2 $1^{\mathrm{WAF} 1}$, and pRB2/p130. The CYR61-transfected cells also formed markedly smaller tumors in nude mice compared with the control cells (22). Down-regulation of CYR61 expression might contribute to the progression of cancer by promoting MMP-7 expression in human gastric carcinomas (23). Moreover, the reduction in
CYR61 expression correlated significantly with histological differentiation, depth of invasion, lymphatic invasion, and clinical stage. Indeed, in this study, the CYR61 mRNA down-regulation was significantly associated with lymph node metastasis. Survival of patients with reduced expression of CYR61 mRNA was lower than in those with normal or increased expression of CYR61 mRNA, according to KaplanMeier analyses. CYR61 mRNA expression status also remained an independent prognostic factor in multivariate analysis. These results suggested that the level of CYR61 mRNA expression is associated with the malignant potential of ESCC, as well as the potential for anti-oncogenesis. CYR61 expression is also linked to the prognosis of ESCC.

SDC2 can link cellular components with the ECM, facilitate the formation of higher order complexes at the cell membrane, and the organization of cortical F-actin. The syndecan family regulates cell/substrate adhesion in part by directly binding to ECM molecules such as fibronectin (24). Recently, SDC2 was considered an upstream switch for the TGF- $\beta$ signaling pathway $(5,6)$. Moreover, CYR61 was shown to be a transcriptional target of TGF- $\beta$ signaling (14). These data provide evidence for an association between SDC2 and CYR61 through the TGF- $\beta$ signaling pathways and prompted us to examine the correlation between SDC2 and CYR61 mRNA expression. Based on our analysis of the relationship between SDC2 and CYR61 mRNA expression, we report a positive correlation between SDC2 and CYR61 mRNA expression in the 77 ESCC cases included in this study $(\mathrm{r}=0.770 ; \mathrm{P}<0.001)$. The statistical analysis also showed that down-regulation of SDC2/CYR61 mRNA expression was significantly associated with regional lymph node metastasis and advanced TNM stage. Furthermore, low SDC2/CYR61 mRNA expression correlated with shortened life span in patients with ESCC after surgery. Thus, SDC2 may regulate and activate the TGF- $\beta$ signaling pathway, resulting in CYR61 transcription. In summary, SDC2 and CYR61 are aberrantly 
expressed in ESCC, and are correlated with lymph node metastasis in ESCC. Moreover, low levels of SDC2 and CYR61 mRNA expression in ESCC were closely associated with poor prognosis. Taken together, SDC2 and CYR61 are antioncogenes involved in the progression of ESCC. Moreover, SDC2 and CYR61 mRNA expression can serve as clinical indicators of poor prognosis of ESCC.

\section{Acknowledgements}

We are very grateful to Professor Zhi-Jv Wei from the Multidisciplinary Research Center (MRC) of Shantou University for technical support for quantitative real-time RT-PCR. Funding was provided by grants from the National High Technology Research and Development Program of China (No. 2006AA02A403), the National Natural Science Foundation of China (No. 30672376, No. 30772485), the Specialized Research Fund for the Doctoral Program of Higher Education of China (No. 20050560002, No. 20050560003), and the Guangdong Scientific Fund for KeyItems (No. 5104541, No. 7118419).

\section{References}

1. Zhang H, Xu L, Xiao D, Xie J, Zeng H, Cai W, Niu Y, Yang Z, Shen Z and Li E: Fascin is a potential biomarker for early-stage oesophageal squamous cell carcinoma. J Clin Pathol 59: 958-964, 2006.

2. Wang Y, Zhou X, Zhu H, Liu S, Zhou C, Zhang G, Xue L, Lu N, Quan L, Bai J, Zhan Q and Xu N: Overexpression of EB1 in human esophageal squamous cell carcinoma (ESCC) may promote cellular growth by activating beta-catenin/TCF pathway. Oncogene 24: 6637-6645, 2005.

3. Lu Z, Liu H, Xue L, Xu P, Gong T and Hou G: An activated Notch1 signaling pathway inhibits cell proliferation and induces apoptosis in human esophageal squamous cell carcinoma cell line EC9706. Int J Oncol 32: 643-651, 2008.

4. Noma K, Smalley KS, Lioni M, Naomoto Y, Tanaka N, El-Deiry W, King AJ, Nakagawa $\mathrm{H}$ and Herlyn M: The essential role of fibroblasts in esophageal squamous cell carcinomainduced angiogenesis. Gastroenterology 134: 1981-1993, 2008.

5. Park H, Han I, Kwon HJ and Oh ES: Focal adhesion kinase regulates syndecan-2-mediated tumorigenic activity of HT1080 fibrosarcoma cells. Cancer Res 65: 9899-9905, 2005.

6. Chen L, Klass C and Woods A: Syndecan-2 regulates transforming growth factor-beta signaling. J Biol Chem 279: 15715-15718, 2004

7. Clasper S, Vekemans S, Fiore M, Plebanski M, Wordsworth P, David G and Jackson DG: Inducible expression of the cell surface heparan sulfate proteoglycan syndecan-2 (fibroglycan) on human activated macrophages can regulate fibroblast growth factor action. J Biol Chem 274: 24113-24123, 1999.

8. Steinfeld R, Van Den Berghe H and David G: Stimulation of fibroblast growth factor receptor-1 occupancy and signaling by cell surface-associated syndecans and glypican. J Cell Biol 133: 405-416, 1996.
9. Modrowski D, Baslé M, Lomri A and Marie PJ: Syndecan-2 is involved in the mitogenic activity and signaling of granulocytemacrophage colony-stimulating factor in osteoblasts. J Biol Chem 275: 9178-9185, 2000.

10. Han I, Park H and Oh ES: New insights into syndecan-2 expression and tumourigenic activity in colon carcinoma cells. J Mol Histol 35: 319-326, 2004.

11. Park H, Kim Y, Lim Y, Han I and Oh ES: Syndecan-2 mediates adhesion and proliferation of colon carcinoma cells. J Biol Chem 277: 29730-29736, 2002.

12. Gulyás M and Hjerpe A: Proteoglycans and WT1 as markers for distinguishing adenocarcinoma, epithelioid mesothelioma, and benign mesothelium. J Pathol 199: 479-487, 2003.

13. Munesue S, Yoshitomi Y, Kusano Y, Koyama Y, Nishiyama A, Nakanishi H, Miyazaki K, Ishimaru T, Miyaura S, Okayama M and Oguri K: A novel function of syndecan-2, suppression of matrix metalloproteinase-2 activation, which causes suppression of metastasis. J Biol Chem 282: 28164-28174, 2007.

14. Bartholin L, Wessner LL, Chirgwin JM and Guise TA: The human Cyr61 gene is a transcriptional target of transforming growth factor beta in cancer cells. Cancer Lett 246: 230-236, 2007.

15. Jiang WG, Watkins G, Fodstad O, Douglas-Jones A, Mokbel K and Mansel RE: Differential expression of the CCN family members Cyr61, CTGF and Nov in human breast cancer. Endocr Relat Cancer 11: 781-791, 2004.

16. Chien W, Kumagai T, Miller CW, Desmond JC, Frank JM, Said JW and Koeffler HP: Cyr61 suppresses growth of human endometrial cancer cells. J Biol Chem 279: 53087-53096, 2004.

17. Tsai MS, Bogart DF, Castañeda JM, Li P and Lupu R: Cyr61 promotes breast tumorigenesis and cancer progression. Oncogene 21: 8178-8185, 2002.

18. Xie D, Yin D, Tong X, O'Kelly J, Mori A, Miller C, Black K, Gui D, Said JW and Koeffler HP: Cyr61 is overexpressed in gliomas and involved in integrin-linked kinase-mediated Akt and beta-catenin-TCF/Lef signaling pathways. Cancer Res 64: 1987-1996, 2004.

19. Di Martino E, Wild CP, Rotimi O, Darnton JS, Olliver RJ and Hardie LJ: IGFBP-3 and IGFBP-10 (CYR61) up-regulation during the development of Barrett's oesophagus and associated oesophageal adenocarcinoma: potential biomarkers of disease risk. Biomarkers 11: 547-561, 2006.

20. Babic AM, Kireeva ML, Kolesnikova TV and Lau LF: CYR61, a product of a growth factor-inducible immediate early gene, promotes angiogenesis and tumor growth. Proc Natl Acad Sci USA 95: 6355-6360, 1998 .

21. Xie D, Miller CW, O'Kelly J, Nakachi K, Sakashita A, Said JW, Gornbein J and Koeffler HP: Breast cancer. Cyr61 is overexpressed, estrogen-inducible, and associated with more advanced disease. J Biol Chem 276: 14187-14194, 2001.

22. Tong X, Xie D, O'Kelly J, Miller CW, Muller-Tidow C and Koeffler HP: Cyr61, a member of CCN family, is a tumor suppressor in non-small cell lung cancer. J Biol Chem 276: 47709-47714, 2001.

23. Maeta N, Osaki M, Shomori K, Inaba A, Kidani K, Ikeguchi M and Ito H: CYR61 downregulation correlates with tumor progression by promoting MMP-7 expression in human gastric carcinoma. Oncology 73: 118-126, 2007.

24. Beauvais DM and Rapraeger AC: Syndecans in tumor cell adhesion and signaling. Reprod Biol Endocrinol 2: 3, 2004. 